\title{
Differentiation of mating system, life history and floral traits in annual and perennial populations of an insect-pollinated plant
}

\author{
Yue Ma ${ }^{1}$, Spencer Barrett ${ }^{2}$, Fang-Yuan Wang $^{1}$, Jun-Chen Deng ${ }^{1}$, and Wei-Ning Bai ${ }^{1}$ \\ ${ }^{1}$ Beijing Normal University College of Life Sciences \\ ${ }^{2}$ University of Toronto
}

May 5, 2020

\begin{abstract}
Theory predicts that selfing should be more prevalent among annuals than perennials, a pattern confirmed by comparative evidence. Yet, intraspecific comparisons between annual and perennial populations are few because such variation is rare among flowering plants. Here, we investigate relations between mating systems and life-history traits between annual and perennial plants of Incarvillea sinensis, a wide-ranging insect-pollinated herb native to China. We estimated outcrossing rates and biparental inbreeding in 16 allopatric and five sympatric populations in which both life histories co-existed using 20 microsatellite loci. In each population we measured plant height, branch number, corolla size, tube length and herkogamy for 30 individuals. In a sympatric population, we recorded daily flower number, pollinator visitation and collected data on fruit and seed set of annual and perennial plants. As predicted, outcrossing rates (t) were considerably higher in perennial (mean $=0.76)$ than annual (mean $=0.09$ ) populations, with the degree of herkogamy consistently larger in outcrossing populations. Perennial populations were more branched with more flowers which were larger in size than in annual populations. In sympatric populations, annuals had significantly higher fruit and seed set than perennials. Differences in herkogamy between annual and perennial plant likely play a key role in governing outcrossing rates. The maintenance of mating system and life-history trait differentiation in I. sinensis probably results from correlated evolution in response to local environmental conditions.
\end{abstract}

\section{Hosted file}

Ma et al.-MS-Feb 13- 2020.doc available at https://authorea.com/users/298475/articles/427764differentiation-of-mating-system-life-history-and-floral-traits-in-annual-and-perennialpopulations-of-an-insect-pollinated-plant 

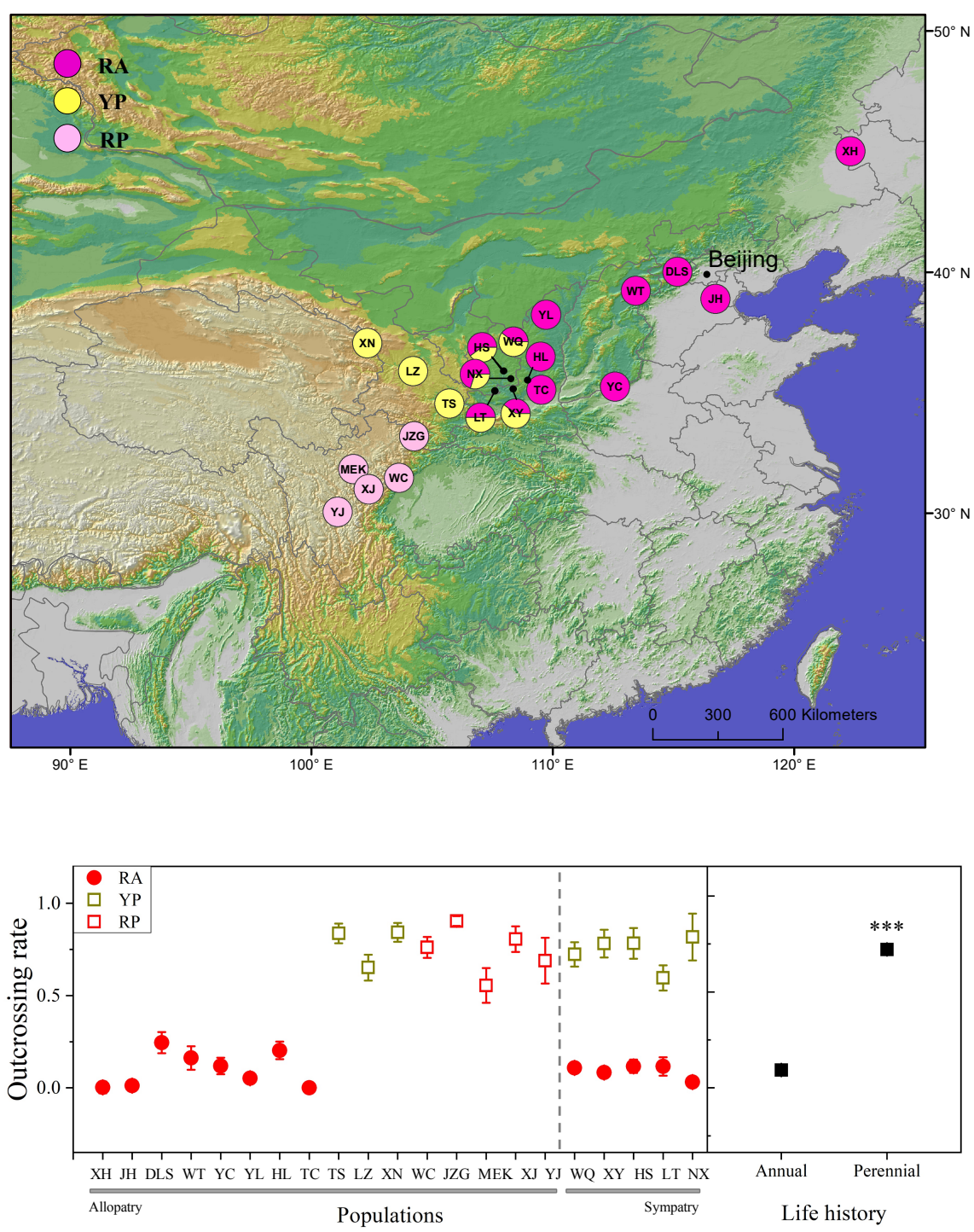

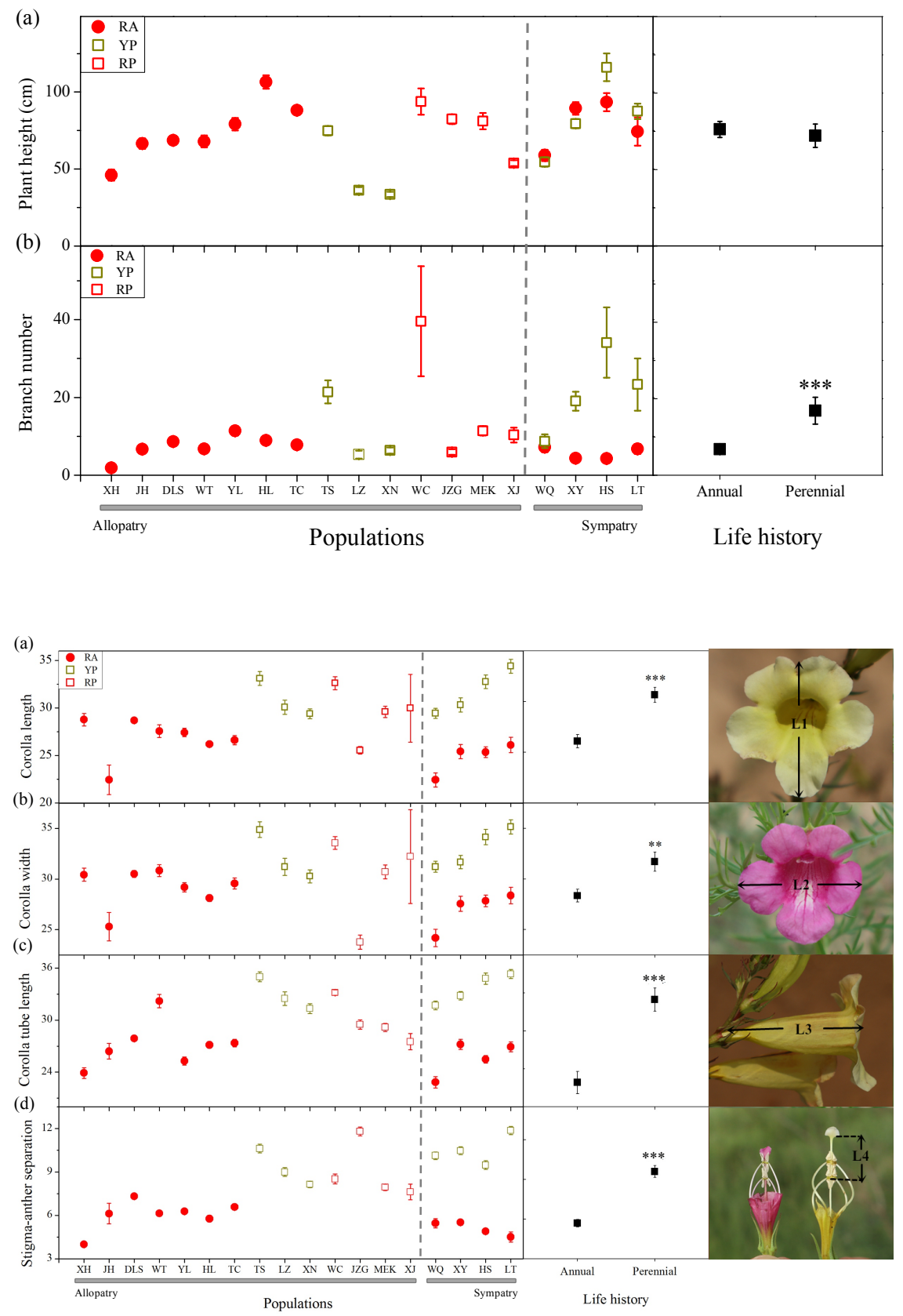


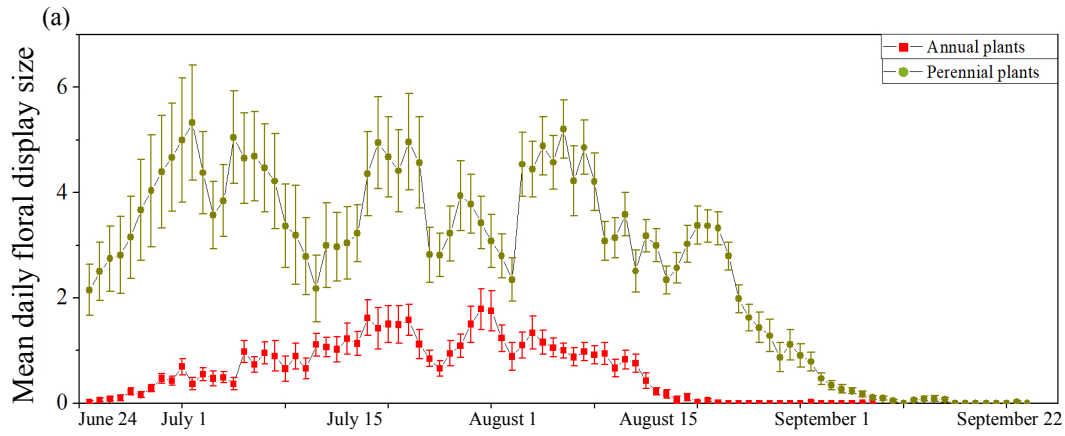

(b)

Flowering season

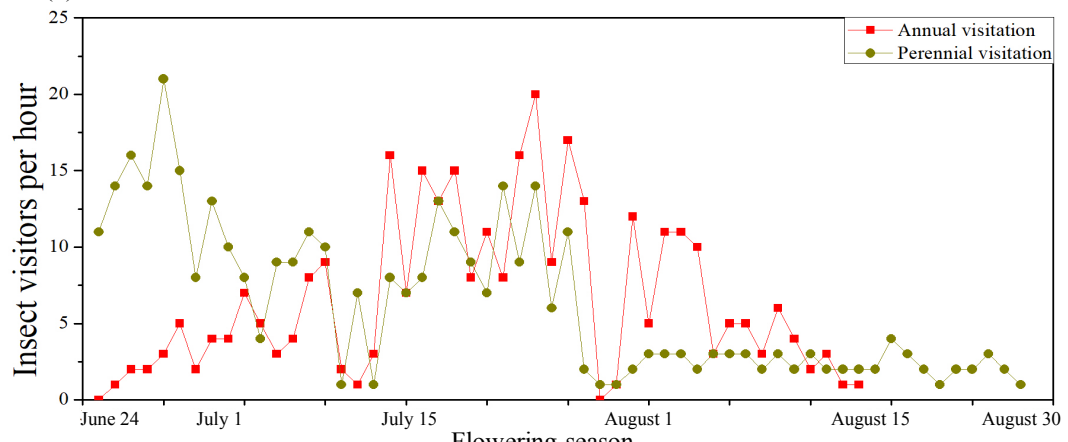

(c)

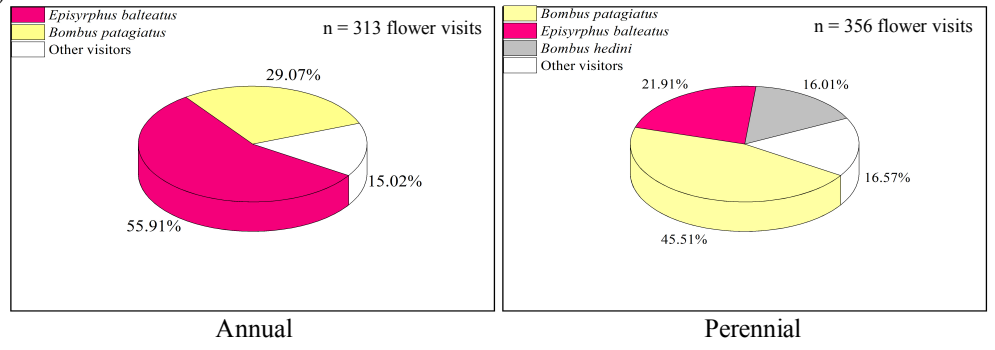




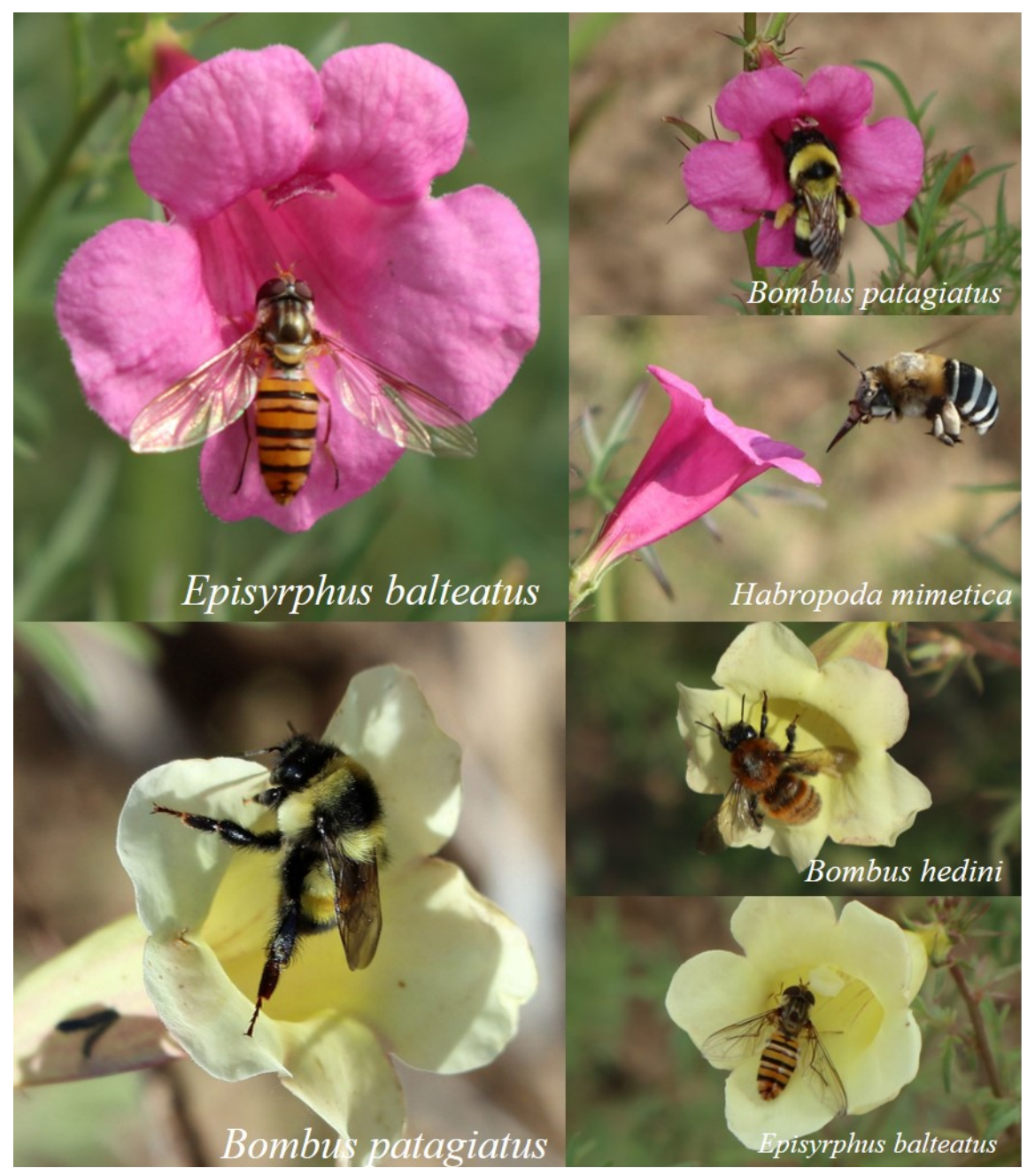



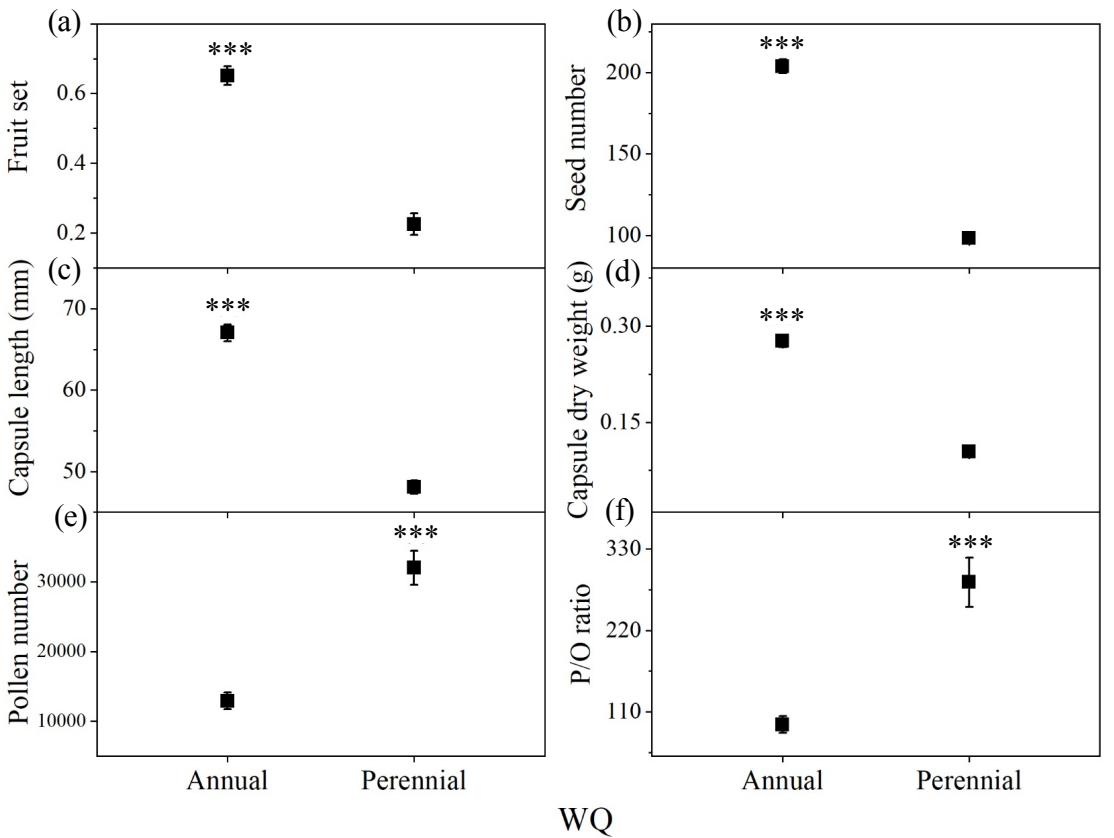